\title{
Standardization of the Self Control and Self-management Skills Scale SCMS on the Student of University of Najran
}

\author{
Marwan Saleh Al-Smadi ${ }^{1, *}$, Yahya Mohammed Bani-Abduh ${ }^{1,2}$ \\ ${ }^{1}$ Department of Education and Psychology, Najran University, Kingdom of Saudi Arabia \\ ${ }^{2}$ Deanship of Development and Quality, Najran University, Kingdom of Saudi Arabia
}

Copyright $\bigcirc 2017$ by authors, all rights reserved. Authors agree that this article remains permanently open access under the terms of the Creative Commons Attribution License 4.0 International License

\begin{abstract}
This study aimed to Standardizes self-control and self-management skills (SCMS), Mezo 2009, on students in the university of Najran And to identify the psychometric properties of the scale in the Arab Environment the society of Najran University student by taking a number of Procedures (Validity and reliability of the Scale ) and to get the Arabic version of self-control and self-management skills (SCMS; Mezo, 2009), Where the scale was applied on a sample of (288) students to verify truthfulness exploratory factorial, as well as cubits on a sample of 120 students to verify the genuineness of consistency, the results of Exploratory Factor Analysis, where self-control and the skills of self-management for scale (Mezo, P. 2009) was applied after making some modifications for the items of the third dimension, and to verify the factorial validity has been conducted Exploratory Factor Analysis of the responses of the study sample, it was conducted a factor analysis of the items of this scale in a way the Principal Component analysis, The results of the study showed that the self-control and self-management skills scale for Mezo, P. 2009 was enjoyed with factorial validity where it was reached to two factors: the first factor, a pure factor loading $(80.4 \%)$ of the variation where all items of the scale has been loaded except the first item "When I work toward something, it gets all my attention" and the second factor: Is also a pure factor loading (59.5\%) of the variation where loading of items of each of the first and the second of sub-scales in the original version of the scale on this factor, while one item only of the third sub-scale in the original scale was not loaded, In the light of this the first factor was named self-evaluating and reinforcing, and consists of 10 items, and the second factor: self-monitoring, and consists of (6) items, so the results of the study showed there is a theoretical building behind this scale, which is an acceptable indication of the validity of the scale in the Arab environment.
\end{abstract}

Keywords Self Control, Self-management Skills

\section{Introduction}

Individuals live in communities governed by laws and regulations and the nature relations between individuals and between them is organized on the basis of their values, customs, traditions, and social foundations, so an individual must comply with those laws and regulations governing the lives of individuals and society so that sets off on his behavior and practice of combined constants to control those behaviors and practices to fit into the society of socially acceptable behaviors.

The ability of the individual to control himself is one of the mental health conditions, the normal individual is the one who can control the desires, and be able to defer the loading of their needs and to give up the immediate pleasures for the sake of reward futures, far-reaching and more lasting, [1], [2] Points to the self-control as an adjustment process of the individual with social norms and laws governing the members of the community, and [3] knew as the internal processes that help the individual to direct his behavior towards the desired activities by changing thoughts and behavior, intentionally or in automated through a range of skills, and [4] knew act in a way that helps to change the results of our behavior, either (Skinner) defined it as an individual to control the environmental effects according to the specific steps to replace a particular behavior, [5], as defined it by the [6] as control the emotions and tolerance when facing with frustration and the ability to delay the rapid loading of their needs, as defined by [7] that a set of declared and hidden activities carried out by the individual to increase or decrease behavior has, and [8] sees the self-control is the ability to subdue the selfish motives of the individual, While [9] sees that self-control is one of the components of self-regulation, unlike [10], who believes that self-regulation and self-control are synonym terms have the same meaning, [11] distinguish between the two types of the control are the direct control that we practice in our daily lives such as an obligation forms appropriate behavior 
or daily routine, self-control that is required foresight about the future and the future vision through self-confidence and sense of self-worth, So the self-control expresses the ability of individuals to command and control over their behavior and practices and their emotions in several ways, through the selection of standards, self-contracts , observation ,self-reward and self-punishment.

Some studies have shown features of the individual who has the ability to self-control, which include: increased perceptions of the individual and his ability to control environmental factors and increase the motivation to do requested change, and led the individual to reduce dependence on others, $[12,13]$.

The features of the individual who has not the ability to self-control, which include: low mental abilities that affect the emotional practices of the individual and which are not consistent with the values, public morality and customs of the society, as well as the negative view, Dislodging And the belief that the worst human being in existence, so it would seek to imitate others and pander to them easily, [14], [15] pointed that the individual who has not the ability to self-control, not be able to take good decisions and solve the problems as well as The low of a sense of modesty and regret and remorse for the negative actions, so this this personality prefers avoiding and escaping the problems, most psychologists believe that there is a difference between Self- control and Self- organization, where both [7] believe that self-control is devoid of flexibility and independence where the person needs guidance from others as needed to help them, but self- organization is characterized by flexibility and independence, the individual puts his objectives, plans and directs his behavior to adapt with the changed circumstances, [16], Others see $[17,18]$ that all of self-regulation, Self-discipline, Self-determination, Self-guidance and self-management which reflect the self-control.

Skinner has pointed to a term of self-identification as synonymous with self-control $[4,19]$ has put famous model of self-control Which consists of three phases: Self-Monitoring stage, which consists of a description and accurate determination of the behavior of the individual, where the individual pays attention deliberately to his behavior, and collect information about the reasons that guide this behavior that he wants to modify, Self-Evaluating stage, as individual sets standards and goals and the expectations of what should be his behavior, based on information obtained from its monitoring of his behavior, then the individual compares at this stage between the behavior that he has done, and the standards and goals which set, Thus, the individual gets at this stage on the feedback about his behavior, Through which you can modifies his behavior if his behavior still needs to be modified, Self-Reinforcing stage: the individual's Reinforcing of himself if he achieves the goals and standards, which placed because of the resurrection of right behavior, or to punish himself if he does not achieve the goals and standards which placed because of the failure to perform an unwanted behavior.

Self-control is influenced by individual factors such as mental abilities and the level of mental maturity and cognitive abilities which the individual has, studies have shown that there was a positive correlation between the mental abilities of the individual and the level of self-control. [20, 21, 22], as well. Self-control was influenced by the gender variable where studies have shown that females are more self-control than male. [23, 24, 25, 26, 27, 28], Previous studies have also showed that the self-control was influenced by the age [29, 30], Previous experiences $[18,31]$, the economic and social level of the family $[24,32,33]$, and the culture of the society in which the individual lives, [34].

\subsection{Study Problem}

In light of the above, the present study problem can be identified by the following questions:

- What are the psychometric properties of the scale of self-control and self-management skills (SCMS; Mezo, 2009) in the Arab Environment (Saudi Arabia )?

- What are the factorial components of self-control and self-management (SCMS; Mezo, 2009)?

\section{The Method and Procedures}

\subsection{Study Population}

Study population consisted of students of the University of Najran, Saudi Arabia and enrolled for the academic year $2016 / 2017$.

\subsection{Study Sample}

The study sample consisted of (288) students, were selected in a manner simple random, the table (1) below shows the distribution of the study sample distributors according to the study variables:

Table 1. The frequencies and percentages of the sample according to study variables

\begin{tabular}{|c|c|c|c|}
\hline Variable & Categories & repetition & Ratio \% \\
\hline \multirow{3}{*}{ Gender } & male & 128 & 44.4 \\
\cline { 2 - 4 } & female & 160 & 55.6 \\
\hline \multirow{3}{*}{ Collage } & practical & 136 & 47.2 \\
\cline { 2 - 4 } & theoretical & 152 & 52.8 \\
\cline { 2 - 4 } & Total & & 100.0 \\
\hline
\end{tabular}

\subsection{Instrument}

Self-control and self-management skills scale [37] was consisted of (150) items in initial his version, where it was 
reducing its items to (145) item on the recommendation of the arbitrators, and distributed to (3) areas, Self-Monitoring (50) items, Self-Evaluating (54) item, Self-Reinforcing (41) item.

Has been conducting a factor analysis exploratory, it has resulted in reducing the number of items of the scale based on the saturation of items on three factors as follows: Self-Monitoring (6) items, Self-Evaluating (5) items, Self-Reinforcing (5) items.

The response of the scale was according to the Likert scale with six responses, Thus, a whole range scale runs between (0-80), where the higher mark was an indicator to the increased level of self-control, Respondents responses have been classified into five categories as follows: Very low self-control (17) degrees or less, low self-control (18-29) degrees, the average self-control (30-41) degrees, high self-control, (42-53) degree, very high self-control (54) degrees and above.

\section{The Results}

The first: What are the psychometric properties of the scale of self-control and self-management skills [37] in the Arab Environment (Saudi Arabia)?

To identify the psychometric properties of the scale (validity and reliability), it was used two methods to verify the validity (content validity, validity of internal consistency), and two ways to check the reliability (Cronbach's alpha, Test - retest method).

\subsection{Validity of the Scale}

\subsubsection{Content Validity}

The original version of the scale was displayed on specialists to make sure matching meaning and ideas in the measure of the translator with the original measure, it was presented the scale to the specialized arbitrators (10) to judge appropriate degree of items of the Arab version of the scale for the Arab environment, according to a standard $(80 \%)$, the proportion of the agreement between the arbitrators on a single item, and in light of this criterion is not deleted any item of the scale. The response of the scale was according to the Likert scale with five responses, instead of six responses as in the original version According to the recommendation of the arbitrators (apply completely, apply, sometimes, does not apply, does not apply completely). So the scale was developed consisting in the final form and distributed items on the three subscale: as follows: Self-Monitoring (6) items, Self-Evaluating (5) items, Self-Reinforcing (5) items, The degree of the scale was ranging (1-80): the degree of the first dimension was ranging (1-30), the second dimension (1-25), the third dimension (1-25), So the higher the mark was an indication of the increased level of self-control, The scale has been classified into five categories: (1-16) the level of self-control is too low, (18-29) low level of self-control, (30-41) the level of self-control is moderate, (42-53) a high level of self-control, and (54) and more is too high level of self-control.

\subsubsection{Internal Consistency Validity}

Applying self-control and the self-management skills on pilot sample of students from University of Najran scale numbered 130 students to measure the degree of correlation item with total degree of the scale and the degree of sub-scale by calculating the Pearson correlation coefficient, Table 2 shows that: 
Table 2. Internal consistency validity- Pearson correlation coefficient $(\mathrm{N}=130)$

\begin{tabular}{|c|c|c|c|c|c|}
\hline No. & Item & $\begin{array}{c}\text { Self-Monitoring } \\
\text { Subscale }\end{array}$ & $\begin{array}{l}\text { Self-Evaluating } \\
\text { Subscale }\end{array}$ & $\begin{array}{l}\text { Self-Reinforcing } \\
\quad \text { Subscale }\end{array}$ & $\begin{array}{c}\text { Self- Control and } \\
\text { Self-Management } \\
\text { Scale }\end{array}$ \\
\hline & Self-Monitoring Subscale & 1 & $.676^{* *}$ & $.586^{* *}$ & $.874^{* *}$ \\
\hline 1 & $\begin{array}{l}\text { When I work toward something, it gets } \\
\text { all my attention }\end{array}$ & $.816^{* *}$ & $.356^{* *}$ & $.282^{* *}$ & $.584^{* *}$ \\
\hline 2 & I keep focused on tasks I need to do even if I do not like them & $.941^{* *}$ & $.549^{* *}$ & $.490^{* *}$ & $.773^{* *}$ \\
\hline 3 & $\begin{array}{l}\text { I become very aware of what I am doing when I am working towards } \\
\text { a goal }\end{array}$ & $.874^{* *}$ & $.553^{* *}$ & $.459^{* *}$ & $.735^{* *}$ \\
\hline 4 & $\begin{array}{c}\text { I make sure to track my progress regularly when I am working on a } \\
\text { goal }\end{array}$ & $.925^{* *}$ & $.546^{* *}$ & $.480^{* *}$ & $.761^{* *}$ \\
\hline 5 & $\begin{array}{c}\begin{array}{c}\text { I pay close attention to my thoughts when I am working on } \\
\text { something hard }\end{array} \\
\end{array}$ & $.855^{* *}$ & $.711^{* *}$ & $.641^{* *}$ & $.839^{* *}$ \\
\hline \multirow[t]{2}{*}{6} & I know I can track my behavior when working toward a goal & $.799^{* *}$ & $.832^{* *}$ & $.720^{* *}$ & $.881^{* *}$ \\
\hline & Self-Evaluating Subscale & $.676^{* *}$ & 1 & $.867^{* *}$ & $.931^{* *}$ \\
\hline 7 & When I set important goals for myself, I usually achieve them & $.728^{* *}$ & $.908^{* *}$ & $.768^{* *}$ & $.891^{* *}$ \\
\hline 8 & $\begin{array}{l}\text { I seem capable of making clear plans for most problems that come } \\
\text { up in my life }\end{array}$ & $.628^{* *}$ & $.936^{* *}$ & $.780^{* *}$ & $.860^{* *}$ \\
\hline 9 & The goals I achieve mean much to me & $.563^{* *}$ & $.925^{* *}$ & $.814^{* *}$ & $.837^{* *}$ \\
\hline 10 & I have learned that it is important to make plans & $.590^{* *}$ & $.918^{* *}$ & $.770^{* *}$ & $.833^{* *}$ \\
\hline \multirow[t]{2}{*}{11} & $\begin{array}{c}\text { The standards I set for myself are clear and make it easy for me to } \\
\text { judge how I am doing on a task }\end{array}$ & $.591^{* *}$ & $.911^{* *}$ & $.860^{* *}$ & $.858^{* *}$ \\
\hline & Self-Reinforcing Subscale & $.586^{* *}$ & $.867^{* *}$ & 1 & $.882^{* *}$ \\
\hline 12 & I congratulate myself when I make some progress & $.503^{* *}$ & $.672^{* *}$ & $.833^{* *}$ & $.723^{* *}$ \\
\hline 13 & $\begin{array}{l}\text { I get myself through hard things by planning to enjoy myself } \\
\text { afterwards }\end{array}$ & $.600^{* *}$ & $.915^{* *}$ & $.894^{* *}$ & $.874^{* *}$ \\
\hline 14 & I silently praise myself even when others do not praise me & $.534^{* *}$ & $.830^{* *}$ & $.949^{* *}$ & $.830^{* *}$ \\
\hline 15 & When I do something right, I take time to enjoy the feeling & $.509^{* *}$ & $.740^{* *}$ & $.927^{* *}$ & $.780^{* *}$ \\
\hline \multirow[t]{2}{*}{16} & I give myself something special when I make some progress & $.419^{* *}$ & $.633^{* *}$ & $.776^{* *}$ & $.654^{* *}$ \\
\hline & Self- Control and Self-Management Scale & $.874^{* *}$ & $.931^{* *}$ & $.882^{* *}$ & 1 \\
\hline
\end{tabular}

**. Correlation is significant at the 0.01 level (2-tailed).

*. Correlation is significant at the 0.05 level (2-tailed).

Note. SM: Self-Monitoring. SE: Self-Evaluating. SR: Self-Reinforcing. SCM: Self- Control and Self-Management

The results showed (Table 2) that the Pearson correlation coefficients between the items and sub-scale, which are belonged to, as well as the, sub-scales with the total scale at the level (0.01), suggesting to achieve the validity of internal consistency of the scale.

Results of the study also showed in the table (2) that the self-control and the of self-management skills for mezzo, (2005) validity of consistency, ranging values of the correlation coefficient between the items of the first dimension with a sub-scale first (0.799 - 0.925), and the correlation coefficient values ranged between items of sub-scale first with the degree of the total-scale $(0.584-0.881)$, all of which are statistically significant at the level of significance $(0.01)$, and the correlation coefficient values ranged between items of the second dimension with the second sub-scale $(0.908-0.925)$, and the values of the items of the second sub-scale correlation coefficient with the degree of the total-scale $(0.833-0.891)$, all of which are statistically significant at the level of significance $(0.01)$, and ranged from the values of the correlation coefficient between the paragraphs of the third dimension with the third sub-scale $(0.776-0.949)$, and the values of factor of correlation the items of the third sub-scale with the degree of the total scale $(0.654-0.874)$, all of which are statistically significant at the level of significance $(0.01)$.

\subsection{The reliability of the Scale}

To examine the reliability of the questionnaire, The Cronbach's Alpha was calculated. This technique revealed a high reliability coefficient $(0.92)$. In addition, the reliability of the questionnaire was estimates by using Test - retest method. This technique revealed a high reliability coefficient (0.89) as Table (3) Shows. 
Table.3. Reliability estimates of the Self- Control and Self-Management Scale, Self-Monitoring Subscale Self-Evaluating Subscale and Self-Reinforcing Subscale

\begin{tabular}{|c|c|c|}
\hline Self- Control and Self-Management & Coefficient alpha & Test-retest correlation Coefficient $(\mathrm{n}=120)$ \\
\hline Self- Control and Self-Management Scale & 0.92 & $0.89^{*}$ \\
\hline Self-Monitoring Subscale & 0.87 & $0.84^{*}$ \\
\hline Self-Evaluating Subscale & 0.85 & $0.82^{*}$ \\
\hline Self-Reinforcing Subscale & 0.88 & $0.85^{*}$ \\
\hline
\end{tabular}

Note. a Test-retest coefficients are based on a subset sample of $120 .{ }^{*} \mathrm{p}<0.05$

Table 4. Total Variance Explained

\begin{tabular}{|c|c|c|c|c|c|c|c|c|c|}
\hline \multirow{2}{*}{ Component } & \multicolumn{3}{|c|}{ Initial Eigenvalues } & \multicolumn{2}{c|}{ Extraction Sums of Squared Loadings } & \multicolumn{3}{c|}{ Rotation Sums of Squared Loadings } \\
\hline & Total & \% of Variance & Cumulative \% & Total & \% of Variance & Cumulative \% & Total & \% of Variance & Cumulative \% \\
\hline 1 & 10.607 & 66.295 & 66.295 & 10.607 & 66.295 & 66.295 & 7.527 & 47.047 & 47.047 \\
\hline 2 & 1.895 & 11.846 & 78.141 & 1.895 & 11.846 & 78.141 & 4.975 & 31.094 & 78.141 \\
\hline 3 & .847 & 5.296 & 83.437 & & & & & & \\
\hline 4 & .592 & 3.698 & 87.135 & & & & & & \\
\hline 5 & .478 & 2.986 & 90.121 & & & & & & \\
\hline 6 & .341 & 2.134 & 92.256 & & & & & & \\
\hline 7 & .260 & 1.626 & 93.881 & & & & & & \\
\hline 8 & .209 & 1.306 & 95.188 & & & & & & \\
\hline 9 & .170 & 1.065 & 96.253 & & & & & & \\
\hline 10 & .148 & .926 & 97.179 & & & & & & \\
\hline 11 & .120 & .752 & 97.931 & & & & & & \\
\hline 12 & .113 & .706 & 98.636 & & & & & & \\
\hline 13 & .073 & .454 & 99.090 & & & & & & \\
\hline 14 & .060 & .378 & 99.468 & & & & & & \\
\hline 15 & .043 & .270 & 99.738 & & & & & & \\
\hline 16 & .042 & .262 & 100.000 & & & & & \\
\hline
\end{tabular}

Extraction Method: Principal Component Analysis

The Self Control and Self-Management Skills Scale (SCMS; Mezo, 2009) enjoyed with reliability properties where the reliability coefficient values ranged $(0.85-0.92)$, by the way of Cronbach's alpha and reliability coefficient values ranged $(0.85-0.92)$, by Test and retest method through the Pearson correlation coefficient at the total scale and sub-scales $(0.82-0.89)$, and all of which are statistically significant at the level $(0,05)$.

The second: What are the factorial components of the Self Control and Self-Management Skills Scale?

Using of Exploratory Factor Analysis, where the self-control and the self-management skills [37] are applied after making some modifications on the items of the third dimension on a sample of 288 male and female students, and to verify the factorial validity of the scale was conducted Exploratory Factor Analysis of the responses of the study sample members, by the Principal Component analysis methods (hotteling), which is one of the most factor analytical methods accuracy and extracted every factor which more variation as possible, As it is rotated axes by Varimax with Kaiser Normalization method. [35] In an effort toward greater purity and clarity in the psychological meaning of loading of items on the factors it has been considered appropriate saturation is a (0.3) and more according to the test of Guilford, [36].
It is clear from the [ (4) the study has been reached factors due to the fact that the values in kind (the underlying root) is greater than the right one, has also been reached proportions interpret the variations of the total variance for every factor.

It is clear from the table (4), the study has been reached two factors due to the fact that the potential root is greater than the right one, has been interpreted as a whole (\%78.14) of the total variation, where the first factor explained by (\%66.29), and the second factor (\%11.84) and, accordingly, were obtained two factors: the first factor is called selfevaluating and self-reinforcing which is a pure factor, obtaining a loading (80.4\%), and the second factor of self-control, which is a pure factor, obtaining a loading $(59.5 \%)$ and table (5) shows as follow:

Table 5. Component Transformation Matrix

\begin{tabular}{|c|c|c|c|}
\hline \multicolumn{2}{|c|}{ Component } & 1 & 2 \\
\hline & 1 & .804 & .595 \\
\cline { 2 - 4 } & 2 & $-.595-$ & .804 \\
\hline
\end{tabular}

Extraction Method: Principal Component Analysis, Rotation Method: Varimax with Kaiser Normalization

It was also rotated axes by the method Varimax with Kaiser Normalization and Table (6) shows the terms of items that were satisfied the factors after the Rotating process: 
Table 6. Rotated Component Matrix

\begin{tabular}{|c|c|c|c|}
\hline \multirow{2}{*}{ No. } & & \multicolumn{2}{c|}{ Component } \\
\cline { 2 - 5 } & & -1 & 2 \\
\hline 1 & Scale Item & $.029-$ & .824 \\
\hline 2 & I keep focused on tasks I need to do even if I do not like them & .362 & .865 \\
\hline 3 & I become very aware of what I am doing when I am working towards a goal & .377 & .797 \\
\hline 4 & I make sure to track my progress regularly when I am working on a goal & .475 & .749 \\
\hline 5 & I pay close attention to my thoughts when I am working on something hard & .585 & .689 \\
\hline 6 & I know I can track my behavior when working toward a goal & .660 & .611 \\
\hline 7 & When I set important goals for myself, I usually achieve them & .795 & .395 \\
\hline 8 & I seem capable of making clear plans for most problems that come up in my life & .830 & .344 \\
\hline 9 & The goals I achieve mean much to me & .776 & .376 \\
\hline 10 & I have learned that it is important to make plans & .873 & .310 \\
\hline 11 & The standards I set for myself are clear and make it easy for me to judge how I am doing on a task & .845 & .245 \\
\hline 12 & I congratulate myself when I make some progress & .890 & .327 \\
\hline 13 & I get myself through hard things by planning to enjoy myself afterwards & .918 & .218 \\
\hline 14 & I silently praise myself even when others do not praise me & .828 & .191 \\
\hline 15 & When I do something right, I take time to enjoy the feeling & .645 & .167 \\
\hline 16 & I give myself something special when I make some progress & & \\
\hline
\end{tabular}

Extraction Method: Principal Component Analysis.

Rotation Method: Varimax with Kaiser Normalization

a. Rotation converged in 3 iterations.

It is clear from the table (6) All items of the scale were loading on the two factors and thus, suggesting the existence of a theoretical building behind this scale, which is an acceptable indication of the validity of the scale.

As the items has been distributed on the scale employed by the degree of loading and the table, (7) shows that:

Table 7. The items of the first factor of Self-Evaluating and reinforcing and the second factor of Self-Monitoring

\begin{tabular}{|c|c|c|}
\hline No. & Item & Degree of loading \\
\hline \multicolumn{3}{|c|}{ first factor: Self-Evaluating and reinforcing } \\
\hline 1 & When I set important goals for myself, I usually achieve them & .660 \\
\hline 2 & I seem capable of making clear plans for most problems that come up in my life & .795 \\
\hline 3 & The goals I achieve mean much to me & .830 \\
\hline 4 & I have learned that it is important to make plans & .776 \\
\hline 5 & The standards I set for myself are clear and make it easy for me to judge how I am doing on a task & .873 \\
\hline 6 & I congratulate myself when I make some progress & .845 \\
\hline 7 & I get myself through hard things by planning to enjoy myself afterwards & .890 \\
\hline 8 & I silently praise myself even when others do not praise me & .918 \\
\hline 9 & When I do something right, I take time to enjoy the feeling & .828 \\
\hline 10 & I give myself something special when I make some progress & .645 \\
\hline \multicolumn{3}{|c|}{ second factor : Self-Monitoring } \\
\hline 11 & When I work toward something, it gets all my attention & .824 \\
\hline 12 & I keep focused on tasks I need to do even if I do not like the & .865 \\
\hline 13 & I become very aware of what I am doing when I am working towards a goal & .797 \\
\hline 14 & I make sure to track my progress regularly when I am working on a goal & .844 \\
\hline 15 & I pay close attention to my thoughts when I am working on something hard & .749 \\
\hline 16 & I know I can track my behavior when working toward a goal & .689 \\
\hline
\end{tabular}




\section{Discussion}

The Self Control and Self-Management Skills Scale (SCMS; Mezo, 2005)enjoyed with validity in the Arab environment where the results of the study has been showed that Pearson correlation factor between the items of sub-scale and the total degree of sub-scale on all Alone, and the total score of the scale statistically, which was significant at the level of (0.01), suggesting to internal consistency of validity for self-control and self-management skills (SCMS; Mezo, 2005), where the correlation coefficient values ranged between the first dimension with a sub-scale first items $(0.799-0.925)$, and the values of the sub-scale first with the total degree -scale items coefficient (0.584 - 0.881), and values of the correlation coefficient between the second dimension with the second sub-scale items $(0.908-0.925)$, and the values of correlation coefficient of second sub-scale items with the total degree of scale $(0.833-0.891)$, and ranged from the values of the correlation coefficient between of items of the third dimension with the third sub-scale items $(0.776-0.949)$, and the values of the correlation coefficient third sub-scale items with the total degree of scale $(0.654-0.874)$, all of which are statistically significant at the level of significance (0.01.)the self-control and the self-management skills enjoyed with reliability properties where the reliability coefficient values ranged $(0.85-0.92)$, by the way of Cronbach's alpha and reliability coefficient values ranged (0.85 - 0.92), by Test and retest method through the Pearson correlation coefficient at the total scale and sub-scales $(0.82$ - 0.89), and all of which are statistically significant at the level $(0,05)$, so the findings suggest the enjoyment of self-control and skills of self-management skills for Mezo scale, P. 2005 characteristics of validity and reliability and validity of its application for the Arab environment.

The results of Exploratory Factor Analysis, where self-control and the skills of self-management for scale [37] was applied after making some modifications for the items of the third dimension, and to verify the factorial validity has been conducted Exploratory Factor Analysis of the responses of the study sample, it was conducted a factor analysis of the items of this scale in a way the Principal Component analysis, because of its accuracy and extracted every factor which more variation as possible, as the axes has been rotated by Varimax with Kaiser Normalization. The results of the study showed that the self-control and self-management skills scale [37] was enjoyed with factorial validity where it was reached to two factors: the first factor, a pure factor loading $(80.4 \%)$ of the variation where all items of the scale has been loaded except the first item "When I work toward something, it gets all my attention" and the second factor: Is also a pure factor loading $(59.5 \%)$ of the variation where loading of items of each of the first and the second of sub-scales in the original version of the scale on this factor, while one item only of the third sub-scale in the original scale was not loaded, In the light of this the first factor was named self-evaluating and reinforcing, and consists of 10 items, and the second factor: self-monitoring, and consists of (6) items, so the results of the study showed there is a theoretical building behind this scale, which is an acceptable indication of the validity of the scale in the Arab environment.

\section{Conclusions}

The study recommends that the application of the scale on a large and different samples to make sure the psychometric properties of the scale in different cultures Allowing to obtain criteria to the scale, In addition to conducting studies aimed at identifying the correlation relationship between self-control and self-management skills and other variables.

\section{Acknowledgements}

The research is financed by Najran University. No. NU/SHED/15/028 (Deanship of Scientific Research at Najran University, Kingdome of Saudi Arabia.

\section{REFERENCES}

[1] Sami Abdul qwey, Psychophysiology, 2nd edition, Cairo: Egyptian Renaissance Library, 1995.

[2] Akers,R.L Self-Control as a general theory of crime, Journal of Quantitative Criminology,Vol.7, no.2, pp. 201-211, 1991.

[3] Karoly,P, Mechanisms of self-regulation : A system view , Annual Review of Psychology, vol.44,pp.23- 52,1993.

[4] Epstein, R. Skinner as a Self-Manager, Journal Of Applied Behavior Analysis, Vol.30, no.3, pp.545-568, 1997.

[5] Corsini,R. Encyclopedia of Psychology, 2nd edition, Vol. 1 , USA, John Wiley and Sons ,1994.

[6] Marion,M Helping children deal with Anger, Young Children, Vol.52, no. 7, pp.62-67,1997.

[7] Du paul, J. and Hoff, Reducing disruptive behavior in general education classrooms: The use of self-management strategies, School Psychology Review, Vol.27, no.2, pp.290-344,1998.

[8] Abdel Rahman Mohamed personality theories, Cairo: Dar Al Quba for printing, publishing and distribution, 1998.

[9] Zimmerman,B.J.(2000): Attaining self-regulated learning : a social cognitive perspective, San Diego, Academic Press.

[10] Richardson,K, Developmental Psychology - How nature the nurture interact, London, Macmillan press LTD , 2000.

[11] Fox,N. and Calkins,S The development of self-control of Emotion, Motivation and Emotion, Vol.27, no.1, pp.7-26, 2003. 
[12] Hudley,C Problem Behavior in Middle Childhood : Understanding Risk Status and Protective Factors, California, Paper Presented at the Annual Meeting of American Educational research Association, p.37,1999.

[13] Goldstein,P.A. Student Aggression: Prevention, Management, and Replacement Training, New York, Guilford Press , 1994.

[14] La Grang,T. and Silverman,R Low Self-control and Opportunity: Testing the General Theory of crime as an Eplanation for Gender Differences in delinquency, Crimionology,Vol.37,pp.41-72, 1999.

[15] Salahuddin Abdul Ghani, Mental Health, Cairo: Dar Al faker Alaraby, 2000.

[16] Heather,M. and Greely,G self-control and the addictive behaviors, Australia, Maxwell Publishing, 1991.

[17] Purdie,N, Self-Regulated Behavior: some theoretical Issues, Newcastle, The University of Western Australia , 1994.

[18] Halford,W. Brief Therapy for Couples, New York, Guilford Publications, 2003.

[19] Kanfer,F.and Goldstein,A.P Helping People Change, New York, Pergamon. 1975.

[20] Davis,H.L. and Pratt,C, The development of children's theory of mind: The working memory explanation. Special Issue: Cognitive development, Australian Journal of Psychology, vol.47, no(1), pp. 25-31, 1995.

[21] Carlson, S.M. and Moses,L.J., Individual differences in inhibitory control and children's theory of mind, Child Development, vol.72, pp.1032-1053, 2001.

[22] Keenan,T, The role of working memory and inhibitory control in children's understanding of false belief. Paper presented at the biennial meeting of the Society for Research in Child Development, Albuquerque, New Mexico, 1999.

[23] La Grang, T. and Silverman, R, Low Self-control and Opportunity: Testing the General Theory of crime as an E planation for Gender Differences in delinquency, Crimionology,Vol.37,pp.41-72, 1999.

[24] Gibbs,J.,Giever,D. and Martin,J. Parental Management and Self-control, Journal of Research in Crime and Delinquency, Vol. 35, pp.40-70,1998.
[25] Cochran,J., Wood,P., Sellers,C. and Chamlin,M, An Empirical Test of a General Theory of Crime, Deviant Behavior,Vol.19 ,pp.227-255, 1995.

[26] Wood,P., Bfefferbaum,P. and Arneklev,P, Risk taking and Self-control: Social psychological correlates of Delinquency, Journal of Crime and Justice, vol.16, pp.111-130, 1993.

[27] Gottfredson, M. R. and Hirschi, T. A general theory of crime, Stanford, CA, Stanford University Press, 1990.

[28] Weinberg,M., Katherine,T., and Oslon,L. Gender differences in emotional expressivity and self-regulation during early infancy, Developmental Psychology, Vol.35, no(1), pp.175-188, 1990.

[29] Longshore, D. Self-control and criminal opportunity, Social problems, Vol.45, pp.102-113, 1998.

[30] Taylor,A.F., Frances,E.K and Sullivan,W.C. Views of Nature and Self-Discipline, Journal of Environmental Psychology, Vol. 21, pp.1-15, 2001.

[31] Thompson,R. and Calkins,S.), The double-edge sword: Emotion regulation for children at risk, Development and Psychopathology, Vol.8, pp.163-182, 1996.

[32] Creenchan,E.(1995): A Test of a General Theory of Crime, Csraborough, Canada, Printice Hall, Inc

[33] Campbell, S., Shaw,D. and Gilliom,M. Early externalizing behavior problems: Toddlers and preschoolers at risk for later maladjustment, Development and Psychopathology, vol.12, pp.467- 488, 2000.

[34] Fox,N. and Calkins,S. The development of self-control of Emotion, Motivation and Emotion, Vol.27, no.1, pp.7-26, 2003.

[35] Faraj, Safwat, the factor analysis in the behavioral sciences, Cairo: Dar Al faker Alaraby,, 151, 1980.

[36] Abdul Khaliq, A., basic dimensions of personality, Alexandria: Dar university knowledge, 114, 1987.

[37] Original scale: Peter G. Mezo The Self-Control and Self-Management Scale (SCMS): Development of an Adaptive Self-Regulatory Coping Skills Instrument J Psychopathol Behav Assess 31:83-93, 2009. 